\title{
Using Cellular Automata-Markov Analysis and Multi Criteria Evaluation for Predicting the Shape of the Dead Sea
}

\author{
Maher A. El-Hallaq1, Mohammed 0. Habboub² \\ ${ }^{1}$ Surveying and Geodesy, Civil Engineering Department, The Islamic University of Gaza, Gaza, Palestine \\ ${ }^{2}$ GIS, IT Department, The University College of Applied Science, Gaza, Palestine \\ Email: $\underline{\text { mhallaq@iugaza.edu.ps, mhabboub@ucas.edu.ps }}$
}

Received 9 March 2015; accepted 24 March 2015; published 26 March 2015

Copyright @ 2015 by authors and Scientific Research Publishing Inc.

This work is licensed under the Creative Commons Attribution International License (CC BY). http://creativecommons.org/licenses/by/4.0/

c) (i) Open Access

\begin{abstract}
In order to make a rational prediction of the Dead Sea shape, data were prepared for suitability map creation using Markov Chain analysis and Multi Criteria Evaluation (MCE). Then, Markov Cellular Automata model and spatial statistics were used in prediction and validation processes. The validation process shows a standard Kappa index of 0.9545 which means a strong relation between the model and reality. The predicted shapes of years 2020, 2030 and 2040 follow the same conditions from 1984 to 2010. The predicted areas of 2020, 2030 and 2040 are 610,591 and 574 $\mathrm{km}^{2}$ which are considered a logical extension of the trend from 1984 till 2010 . This study can be used as an environmental alert in order to keep the Dead Sea alive. Moreover, Markov-Cellular Automata model can be used to predict closed seas as the Dead Sea from remote sensed data.
\end{abstract}

\section{Keywords}

Dead Sea, Markov Chain Analysis, Cellular Atutomata, Multi Criteria Evaluation

\section{Introduction}

Reference [1] defines Markovian process as the state of a system at time 2 can be predicted by the state of the system at time 1 by giving a matrix of transition probabilities from each cover class to every other cover class. The application of Markov analysis is basically used to study of land use change and land use impact assessment. Recently, Markov analysis of land use change has been combined with GIS to create a tool for visualizing and projecting the probabilities of land use change among categories of land use. Figure 1 shows a schematic illustration that illustrates the inputs and outputs of Markov chain. 


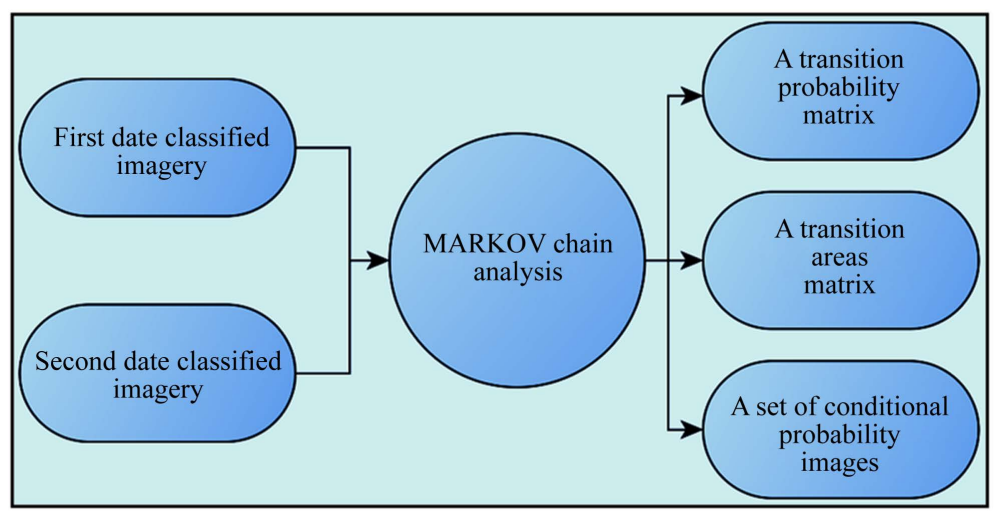

Figure 1. The inputs and outputs of Markov chain.

All landscape spatial transition models can be expressed in a simple matrix as in Equation (1) [2]:

$$
L U_{t+1}=L U_{t} \times P
$$

where $L U_{t}$ is the distribution of land uses among the different types at the beginning of the period and $L U_{t+1}$ is showing the distribution of land use types at the end of the projection period [3] in other words $L U_{t}$ and $L U_{t+1}$ are vectors composed of the fractions of each landscape type at time $t$ and time $t+1$, respectively. Reference [2] defines $P$ as a square matrix, whose cell $P_{i j}$ is the transition probability from landscape $\mathrm{i}$ to $\mathrm{j}$ during times $t$ and $t+1$, while [4] described the transition probability, $P_{i j}$, as the probability of moving from one state $i$ to another state which could be represented in the form of a transition matrix, $P$. Equation (2) illustrates the $P$ matrix. A transition areas matrix expresses the total area (in cells) expected to be changed in the next time period. A set of conditional probability images expresses the probability that each pixel will belong to the designated class in the next time period. They are called conditional probability maps since this probability is conditional on their current state [1].

$$
P=\left[\begin{array}{cccc}
p_{11} & p_{12} & \cdots & p_{1 n} \\
p_{21} & p_{22} & \cdots & p_{2 n} \\
\vdots & \vdots & \ddots & \vdots \\
p_{n 1} & p_{n 2} & \cdots & p_{n n}
\end{array}\right]
$$

The transition probabilities $P$ in $K$ steps are derived from the landscape transitions occurring during some time interval as shown in Equations (3) and (4) [2]:

$$
\begin{gathered}
P_{m}(i, j)=\frac{N(i, j)}{\sum_{k=1}^{k} n_{i j}} \\
P(i, j)=\sum_{k=1}^{k} \frac{P_{m}(i, j)}{K n_{m}}
\end{gathered}
$$

where $N(i, j)$ is the observed data during the transition from state $i$ to $j$, and $n_{i j}$ is the number of years between time step $i$ and step $j$, and the total number of years is $m ; P(i, j)$ is the yearly transition probability after normalizing the transition probability in multiyear and $K$ is the number of steps [2]. The cells in the transition matrix are probabilities; it follows Equation (5).

$$
\sum_{j=1}^{m} P(i, j)=1
$$

One of the disadvantages of Markov chain is that it has a very limited spatial knowledge. To improve the spatial sense of these conditional probability images, using Cellular Automata model will be a good choice. Cellular Automata (CA) is a grid of cells with each cell updating its value based on its neighboring cell values [5] while [1] defines CA as a cellular entity that independently varies its state based on its previous state and that of its immediate neighbors according to a specific rule. Although this definition is so close to Markov chain, the only 
difference is that the application of a transition rule which depends not only upon the previous state, but also upon the state of the local neighborhood. So, the state of a cell is determined by the previous states of the surrounding neighborhood of cells. Each cell in a regular spatial lattice can have any one of a finite number of classes. CA-Markov has the ability to simulate land use changes among multiple categories and combines the CA and Markov chain procedures. Markov analysis does not account for the causes of land use change and it is insensitive to space [4]. IDRISI software illustrates a technique of CA-Markov since a Markov chain analysis is performed in order to estimate the transition matrix between the two past dates and to estimate probabilities of change for the third date to be predicted. Then, CA estimates the spatial distribution of land cover at a later date. Equations (6) and (7) below illustrate the evaluation of cells from time $t$ to $t+1$ is determined by a function of its state, its neighborhood space and a set of transition rule [6].

$$
\begin{aligned}
& L U_{i, j(t+1)}=f\left(L U_{i, j(t)} \cdot S_{i, j(t)} \cdot P_{x, y, i, j(t)} \cdot N_{i, j(t)}\right) \\
& N_{i, j(t)}=\frac{\sum_{t} N_{i, j(t)}}{\# \text { of adjacent cells }}
\end{aligned}
$$

where:

$L U_{i, j(t+1)}$ : The potential of cell $i, j$ to change at time $t+1$,

$L U_{i, j(t)}$ : States of cell $i, j$ at time $t$,

$S_{i, j(t)}:$ Suitability indexes of cell $i, j$ at time $t$,

$P_{x, y, i, j(t)}$ : Probability of cell $i, j$ to change from state $x$ to state $y$ at time $t$ (as shown in Equation (3) above), and;

$N_{i, j(t)}:$ Neighborhood index of cell $i, j$.

A number of previous studies regarding CA-Markov are shown in [6]-[10]. IDRISI software offers a comprehensive statistical analysis that answers how well a pair of maps agrees in terms of the quantity and location of cells in each category, various Kappa Indices of Agreement (KIA) and related statistics have been derived to indicate how well the comparison map agrees with the reference map. These methods of validation have been created recently at Clark University by Gil Pontius. Therefore, there are no explanations of these statistics in common statistical books. It is highly recommended to see [11]-[13] for more information. Validation process determines the disagreement between predicted map and real classified imagery. Two types of disagreement will be calculated; quantity disagreement happens when the quantity of cells of a category in the comparison map is different from the quantity of cells of the same category in the reference map and Allocation disagreement occurs where location of a class in the comparison map is different from location of that class in the reference map [4] and [13]. Reference [13] explains that the motivation to derive Kappa for no information is that $J$ is the statistically expected overall agreement when both the quantity and allocation of categories in the comparison map are selected randomly while Klocation is an index of pure allocation where 1 indicates optimal spatial allocation as constrained by the observed proportions of the categories, and 0 indicates that the observed overall agreement is equal the agreement expected under random spatial reallocation within the comparison map given the proportions of the categories in the comparison and reference maps . Another term is offered by IDRISI, the disagreement at the grid cell level which is the amount of disagreement associated with the fact that the comparison map fails to specify perfectly the correct locations of categories at grid cells within strata. In other words, if we were to rearrange the grid cells within each stratum of the comparison map, then we could improve the agreement between the reference map and the comparison map from $M(m)$ to perfect stratum $K(m) . K(m)=1$ if and only if the proportions of each category in each stratum in the comparison map are the same as the proportions in the reference map.

\section{The Study Area}

The Dead Sea is located on $31^{\circ} 30^{\prime} 0^{\prime \prime} \mathrm{N}, 35^{\circ} 30^{\prime} 0^{\prime \prime E}$, WGS84 coordinate system, bordering Jordan to the east, historical Palestine and the West Bank to the west as illustrated in Figure 2. The Dead Sea is considered as the lowest point on the Earth's surface at about $-400 \mathrm{~m}$ [14]. The east and west shores of the Dead Sea are bounded by towering fault escarpments that form part of the African-Syrian rift system. The valley slopes gently upward to the north along the Jordan River, and to the south along the Wadi Araba. Since 1978, the Dead Sea has retreated, and the sea body turned into two basins: the principal northern one that is about $308 \mathrm{~m}$ deep (in 1997), and the shallow southern one with the Lisan (or Lashon) Peninsula and the Lynch Straits in between, which has 


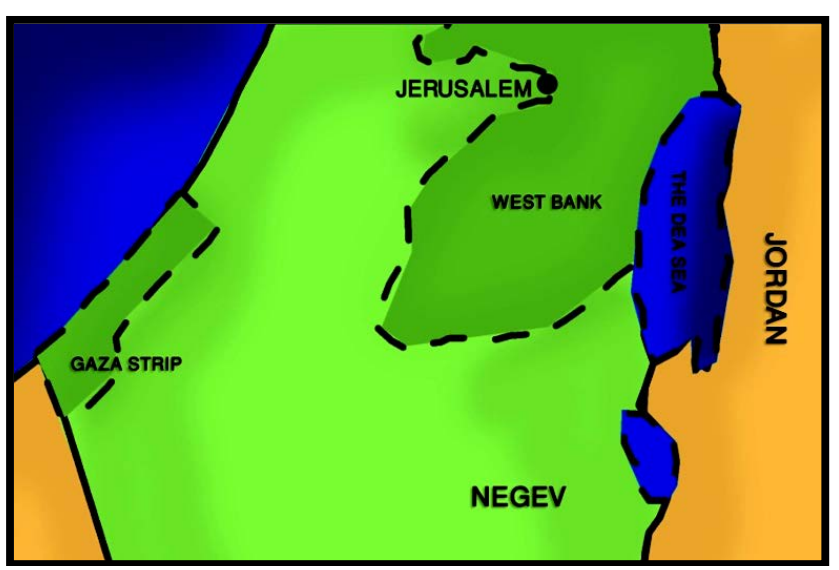

Figure 2. The Dead Sea location.

a sill elevation of about $400 \mathrm{~m}$ below the sea level [15].

This study aims to investigate and predict the shape of the northern part of the Dead Sea using CA-Markov analysis and Multi Criteria Evaluation. For this purpose, the classified data of three Landsat time series satellite images (1984, 2000 and 2010) are to be used. The Dead Sea shape at later dates of 2020, 2030 and 2040 will be created, but first 2010 map will be predicted and compared with the real 2010 classified imagery using the standard Kappa Index and other spatio-statistical parameters.

\section{Framework Methodology}

The methodology followed in this study consists of seven major stages;

1) Data collection: Landsat Imagery download and ASTGTM-DEM of the Dead Sea area.

2) Pre-processing: aims to normalize all imageries by converting Digital Number (DN) to spectral radiance.

Then, atmospheric effects are removed. Moreover, the resulted images are converted to reflectance. Finally, black gaps are removed; if exist.

3) Supervised Classification.

4) Change detection analysis: changes of the Dead Sea area and shape

5) Data preparation for prediction: This stage consists of three tasks:

a) Markov chain analysis.

b) Data generation for Multi Criteria Evaluation (MCE).

c) Suitability map creation.

6) Prediction and validation processes.

7) Results and discussion.

In order to achieve the mentioned methodology, the following software and supporting tools are used. ERDAS Imagine 10 is used for image pre-processing and normalization, supervised classification and bathymetric map creation. Arc-GIS 9.3 is used for spatio-temporal analysis, building models for area, change analysis and Multi Criteria Evaluation, calculating spatial parameters and cartographical representation. IDRISI Selva is used for Markov Cellular Automata prediction analysis and validation process. Stages from 1) to 4) are deeply discussed in [16], thus, concentration will be focused on other stages.

\section{Data Preparation for Prediction}

In terms of future prediction, Markov-Cellular Automata (CA-Markov) model will be used. CA-Markov is a combined Cellular Automata, Markov Chain and Multi-Criteria Evaluation (MCE) land cover prediction procedure that adds an element of spatial contiguity as well as knowledge of the likely spatial distribution of transitions to Markov chain analysis. So, three main processes are required; Markov model, Cellular Automata model and validation and prediction. Figure 3 summaries the main steps in each process of data preparation for prediction which consists of three steps:

Markov analysis needs two imageries as inputs to create a) a transition probability matrix, b) a transition 


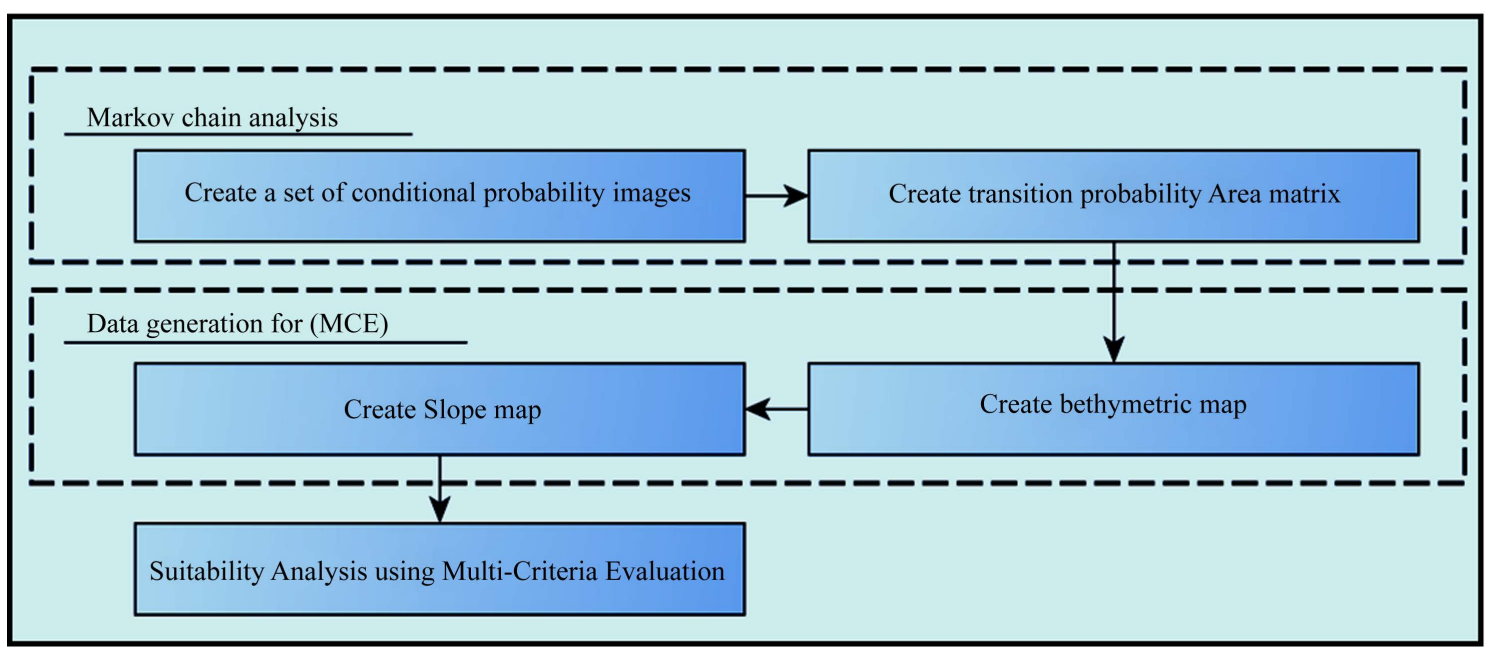

Figure 3. Process used in data preparation for prediction.

area matrix c) a set of conditional probability images. In data generation for MCE, two maps are created; bathymetric map which generated from TM imagery and slope map which generated from ASTGTM-DEM.

As discussed above bathymetric map is one of the essential criteria map for prediction. The measurement of bathymetry can be expected to be the best with Landsat TM data because that sensor detects visible light from a wider portion of the visible spectrum, in more bands, than other satellite sensors. In order to create a bathymetric zones map represents a very crude bathymetric map, the following steps have to be accomplished one by one: First, finding out the average DN values of deep water pixels for blue, green, red and infrared bands of the 2010 Landsat TM image [17]. This is done by finding a block of pixels (2500 pixel are used in this research) in a spot of the water-body known as deep water. Deep water block is identified by the least DN in the imagery. In this research a squared spot centered in (X: 739965E, Y: 3496125N, UTM) is used. Using ERDAS Imagine, a model has been built in order to develop bathymetric zones map, see Figure 4, the model consists of four inputs, and one output. The inputs are the first four bands while the output is the bathymetric zones map.

The values $0,63,127,191$ and 255 are assigned to each zone in order to make it visually recognizable before cartographical presentation. Figure 5 shows the final bathymetric zones map.Slope map is one of the essential criteria map for prediction. The creation of the slope map is a forward process using ArcGIS software-spatial analyst extension. However, the concept of creating slope map is by calculating the difference between DN stored in a ASTGTM-DEM cell and the minimum value on the eight adjacent cells in that ASTGTM-DEM. Then, the calculated difference is divided by the cell size of ASTGTM-DEM. This process is repeated for every cell in ASTGTM-DEM in order to create the slope map. Figure 6 represents ASTGTM-DEM and slope maps. In order to use Cellular Automata, a suitability map for each class is considered as a pre-requirement. Suitability maps are derived using Multi-Criteria Evaluation by combining the information from several criteria to form a single index of evaluation [1]. A weight linear combination equation-Equation (8)—is used to obtain suitability map for the Dead Sea Area.

$$
S=\sum_{i=1}^{n} W_{i} C_{i} \prod_{i=1}^{n} r_{i}
$$

where

$S$ : The suitability map.

$W_{i}$ : Weight for a criteria $i$.

$C_{i}$ : Criteria for suitability.

$r_{i}$ : Restriction.

By applying weights to each rated factor, the suitability map of the Dead Sea Area was developed using three maps; the bathymetric map, the probability of classes map derived from Markov process and the slope map derived from ASTGTM-DEM. More than one trial is made to get the best results in validation. Table 1 illustrates the final weights for each rated map criteria for each suitability map. Using ArcGIS, a model has been built- 


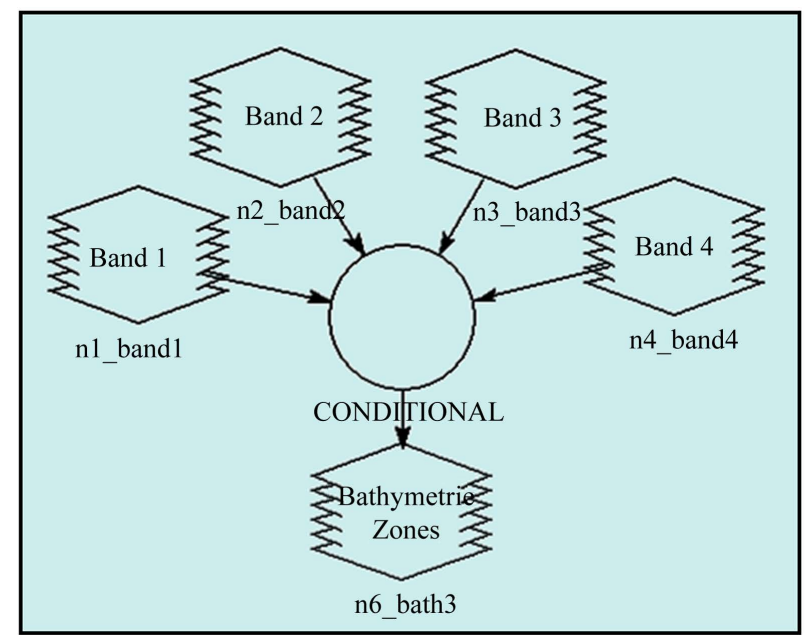

Figure 4. Bathymetric zones map model.

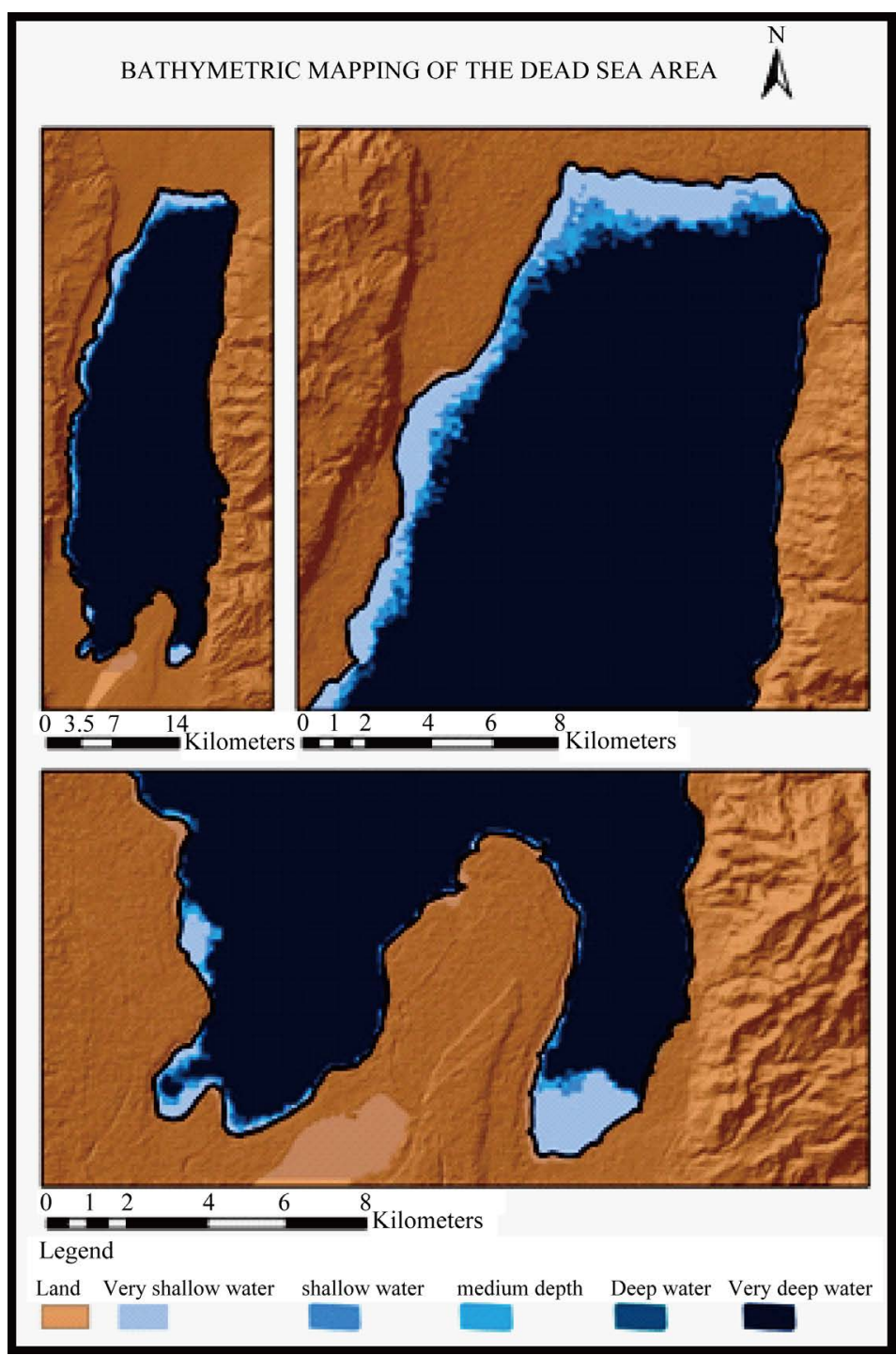

Figure 5. Zones of bathymetric map using the previous model. 


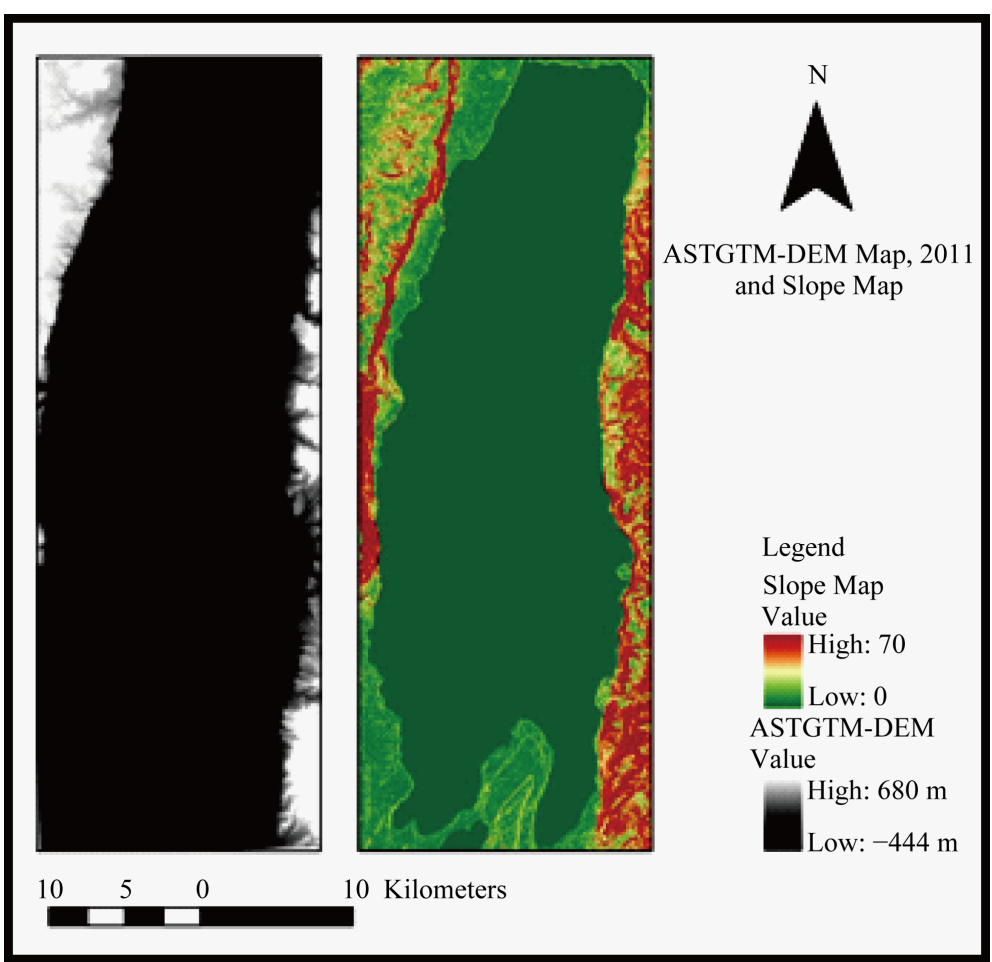

Figure 6. ASTGTM-DEM and slope map.

Table 1. Suitability map criteria weights and rates.

\begin{tabular}{|c|c|c|c|}
\hline \multicolumn{4}{|c|}{ Suitability map for water class } \\
\hline & $i=1$ & $i=2$ & $i=3$ \\
\hline$C_{i}$ : Criteria for suitability & $\begin{array}{l}\text { Bathymetric zones map rated } \\
\text { from } 0.1 \text { to } 1 \text { as very shallow to } \\
\text { very deep water respectively. }\end{array}$ & $\begin{array}{l}\text { The water class probability map } \\
\text { of Dead Sea derived from } \\
\text { Markov process. }\end{array}$ & $\begin{array}{l}\text { Slope map derived from ASTGTM-DEM map } \\
\text { rated from } 0.1 \text { to } 1 \text { as the highest slope to the } \\
\text { lowest slope respectively. }\end{array}$ \\
\hline$W_{i}$ : Weight for a criteria $i$ & $34 \%$ & $33 \%$ & $33 \%$ \\
\hline \multirow[t]{3}{*}{$r_{i}:$ Restriction } & \multicolumn{3}{|c|}{ Area boundaries } \\
\hline & \multicolumn{3}{|c|}{ Suitability map for land class } \\
\hline & $i=1$ & $i=2$ & $i=3$ \\
\hline$C_{i}$ : Criteria for suitability & $\begin{array}{l}\text { Bathymetric zones map rated } \\
\text { from } 0.1 \text { to } 1 \text { as deep to very } \\
\text { shallow water respectively. }\end{array}$ & $\begin{array}{l}\text { The land class probability map } \\
\text { of Dead Sea derived from } \\
\text { Markov process. }\end{array}$ & $\begin{array}{l}\text { Slope map derived from ASTGTM-DEM map } \\
\text { rated from } 0.1 \text { to } 1 \text { as the lowest slope to the } \\
\text { highest slope respectively. }\end{array}$ \\
\hline$W_{i}$ : Weight for a criteria $i$ & $34 \%$ & $33 \%$ & $33 \%$ \\
\hline$r_{i}$ : Restriction & Very deep water & & Area boundaries \\
\hline
\end{tabular}

see Figure 7-to create the suitability map for water/Land class using MCE. The model consists of three inputs, blue ellipses, five tools, umber rectangles, and five outputs one of them is the resulted suitability map. The inputs are the class probability, the bathymetric zones and ASTGTM-DEM maps while the tools are slope generation tool, reclassification tools and weighted overlay tool.

\section{Prediction and Validation}

Using the output data produced by the Markov chain analysis, the predicting model will apply a contiguity filter to grow out from imagery captured in the year of 2000 to a future time. This CA filter develops a spatially explicit contiguity-weighting factor to change the state of a cell based on its neighbors. Dead Sea shape at later 


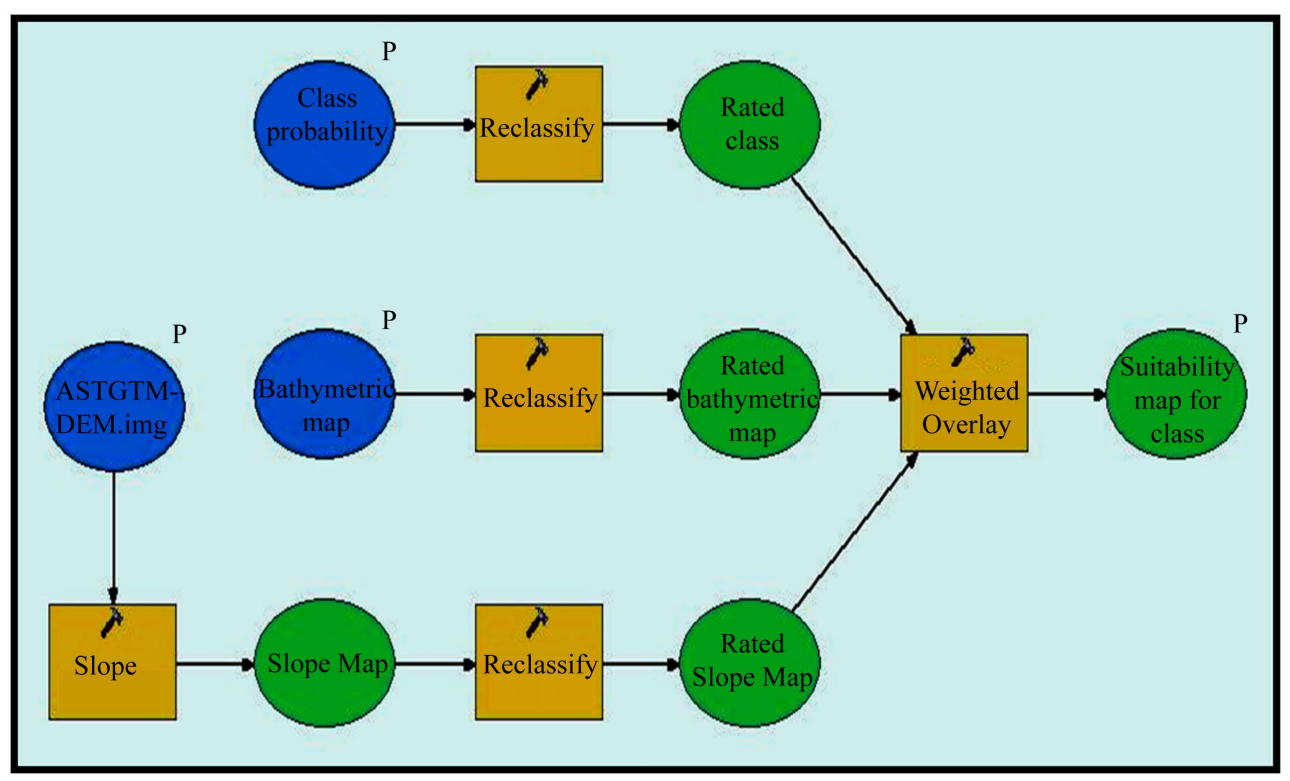

Figure 7. Multi Criteria Evaluation (MCE) model.

dates of 2020, 2030 and 2040 will be created, but first 2010 map will be predicted and compared with the real 2010 classified imagery using the standard Kappa Index and other spatio-statistical parameters. There are three outputs of Markov chain analysis for each predicted year. The following three outputs are resulted from using the classified imageries 1984 and 2000 as inputs in the process of predicting the 2010 map using CA-Markov analysis.

a) A transition areas matrix (1984-2000-2010):

$$
\left[\begin{array}{ccc} 
& \text { Class1(water) } & \text { Class2(Land) } \\
\text { Class1(Water) } & 681062 & 32316 \\
\text { Class2(Land) } & 416 & 1387417
\end{array}\right]
$$

The transition areas matrix (1984-2000-2010) expresses the total area (in cells) expected to change from the year of 2000 to the year of 2010 according to those changes happened from 1984 to 2000. Based on matrix above, there are 416 land classified cells ( $30 \mathrm{~m} /$ cell) will turn into water class, meanwhile there are 32316 water classified cells will turn into land class.

b) Transition probability matrix (1984-2000-2010):

$\left[\begin{array}{ccc} & \text { Class1(water) } & \text { Class2(Land) } \\ \text { Class1(Water) } & 0.9547 & 0.0453 \\ \text { Class2(Land) } & 0.0003 & 0.9997\end{array}\right]$

The transition probability matrix (1984-2000-2010) expresses the likelihood that a pixel of a given class that will change to any other class (or stay the same) in the next time period. This could be derived from transition areas matrix by knowing the total cells of each class.

c) A set of conditional probability images/each class (1984-2000-2010)

These maps (Figure 8(a)) and (Figure 9(a)) express the probability that each pixel will belong to the designated class in the next time period. They are called conditional probability maps since this probability is conditional on their current state. So these maps are a cartographical presentation of the transition probability matrix. Multi Criteria Evaluation is used to create suitability map for land and water classes. Figure 8(b) shows the classified slope map for land class which is rated from 0.1 to 1 as the lowest slope (less convenient to the land) to the highest slope (more convenient to the land) respectively, while Figure 8(c) illustrates the classified bathymetric zones map for land class which is rated from 0.2 to 1 as the very deep water (less convenient to the land) to the very shallow water (more convenient to the land) respectively. The value of 1 is not assigned to the water- 


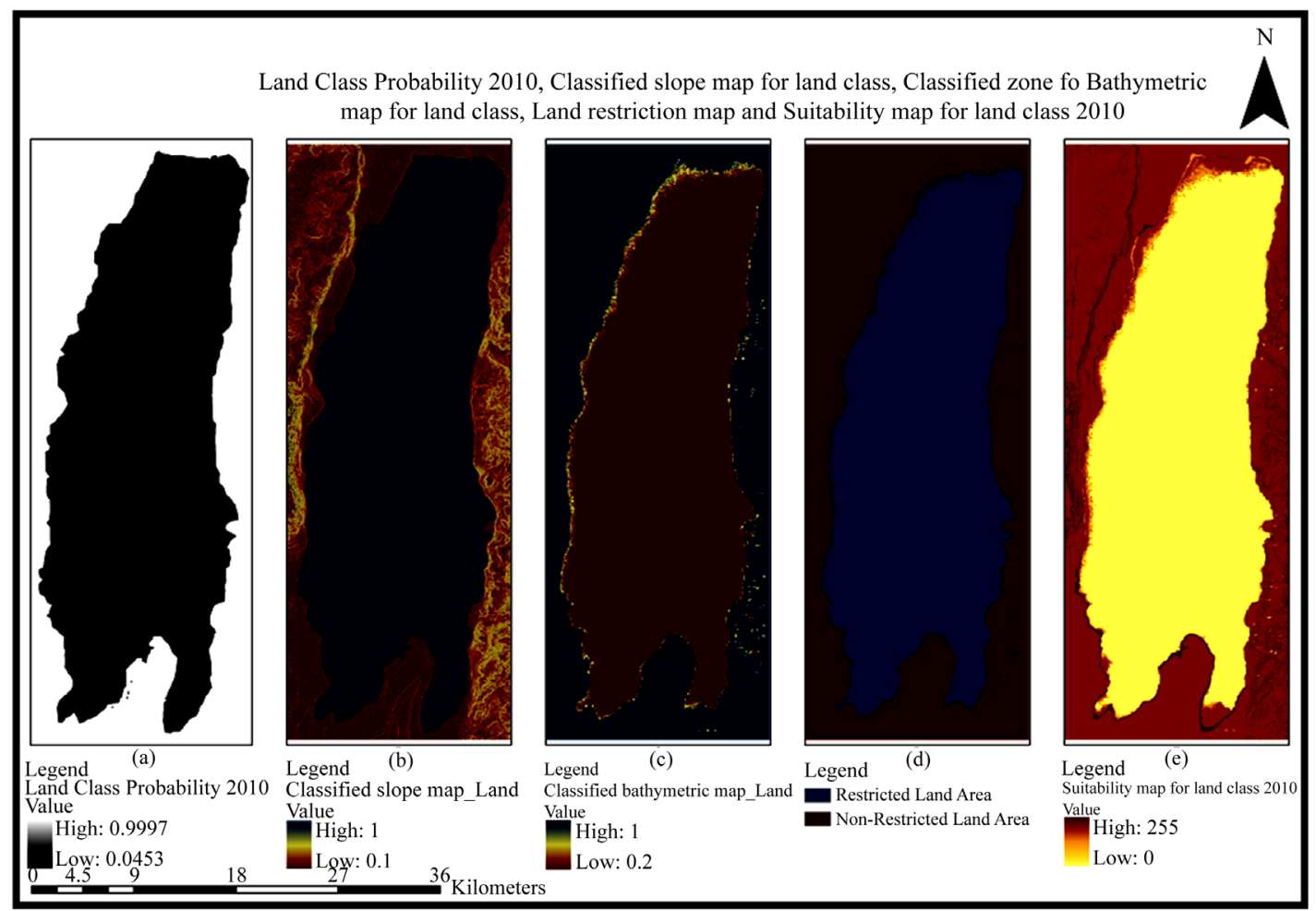

Figure 8. Data used for MCE and suitability map for land class 2010.

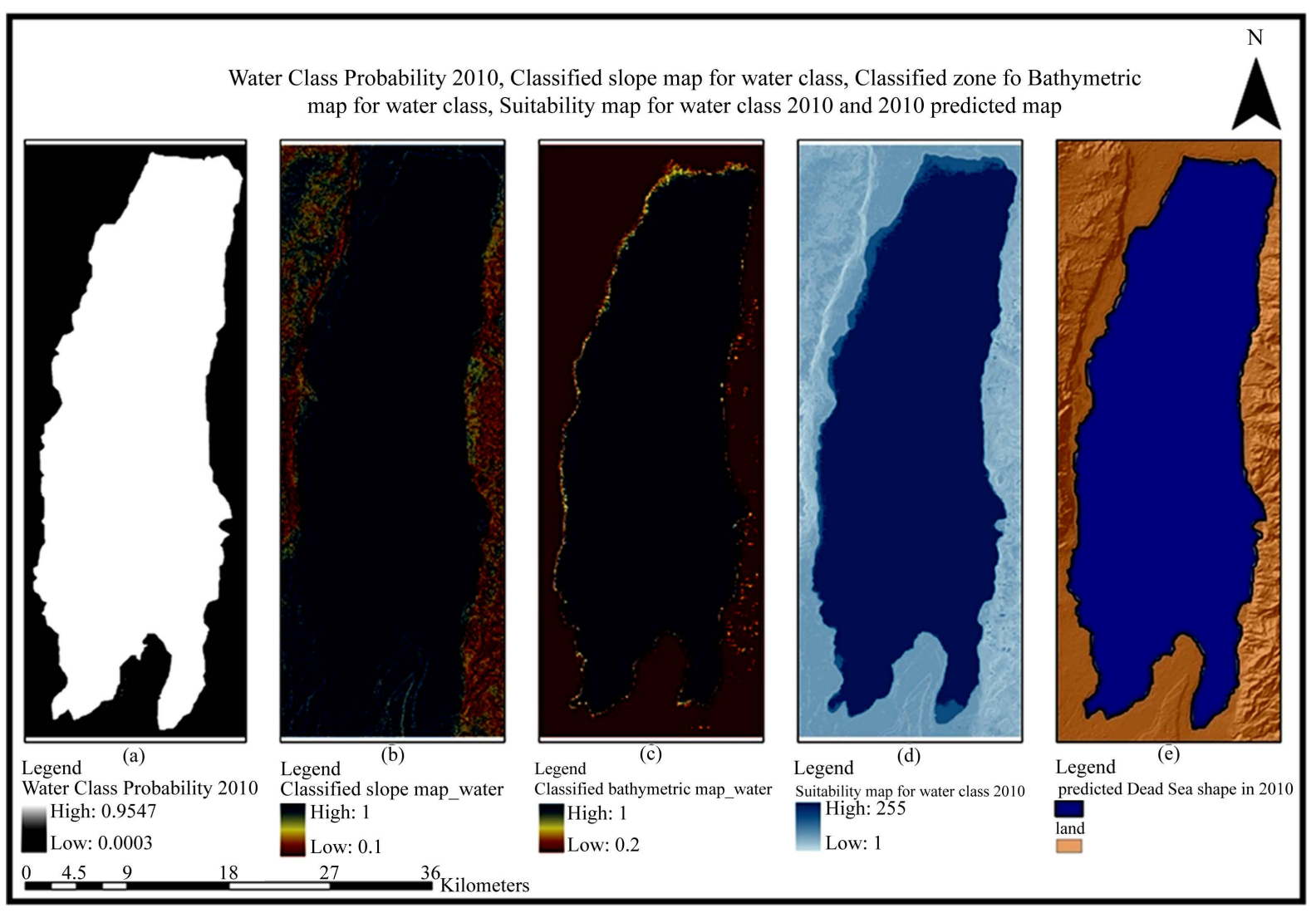

Figure 9. Data used for MCE, suitability map for water class 2010 and 2010 predicted map. 
body for suitability but in order multiply overlaid layers by 1. Land restriction map is shown in Figure 8(d) where deep water area is restricted for land class. Then the corresponding suitability map for land class 2010 is illustrated in Figure 8(e) which is rescaled from 0 - 255 where the more DN (darker) is, the more suitable for land class. In contrast, Figures 9(b)-(d), represent classified slope map for water class, classified bathymetric zones map for water class and suitability map for water class 2010 respectively. It is obvious that the more DN is the more suitable for water class. Figure 9(e) illustrates the corresponding predicted 2010 Dead Sea shape.

\section{Results and Analysis}

By using the output data produced by the Markov chain analysis and MCE analysis, the predicting model applied for the year of 2010. The expected 2010 map is shown in Figure 10. Then, standard Kappa index is used to check whether the model is valid or not (usually the Kappa Index for a valid model is $>70 \%$ ) [8]. If the model has the Kappa Index less than 70\% then the suitability map for the wetland area and/or filter used should be repeated again based on several considerations, otherwise, suitability maps and filter will be used to create the spatial model for 2020, 2030 and 2040 years.

Using VALADATE tool, IDRISI gave the standard Kappa of 0.9545, Kappa for no information of 0.9564, Kappa for grid-cell level location of 0.9981 and Kappa for stratum-level location of 0.9981 Which are all more than 0.7. More-over IDRISI offers quantity disagreement of about 0.0209 , which is convenient with the outputs of the transition matrix. Transitional matrix shows that the water-body will decrease by $28.63 \mathrm{~km}^{2}$ from 2000 to 2010 to equal $613 \mathrm{~km}^{2}$. However; the real 2010 map tells another story since the decrease from 2000 to 2010 was just $10.77 \mathrm{~km}^{2}$ to equal $631.27 \mathrm{~km}^{2}$.

The template is used to format your paper and style the text. All margins, column widths, line spaces, and text fonts are prescribed; please do not alter them. You may note peculiarities. For example, the head margin in this template measures proportionately more than is customary. This measurement and others are deliberate, using

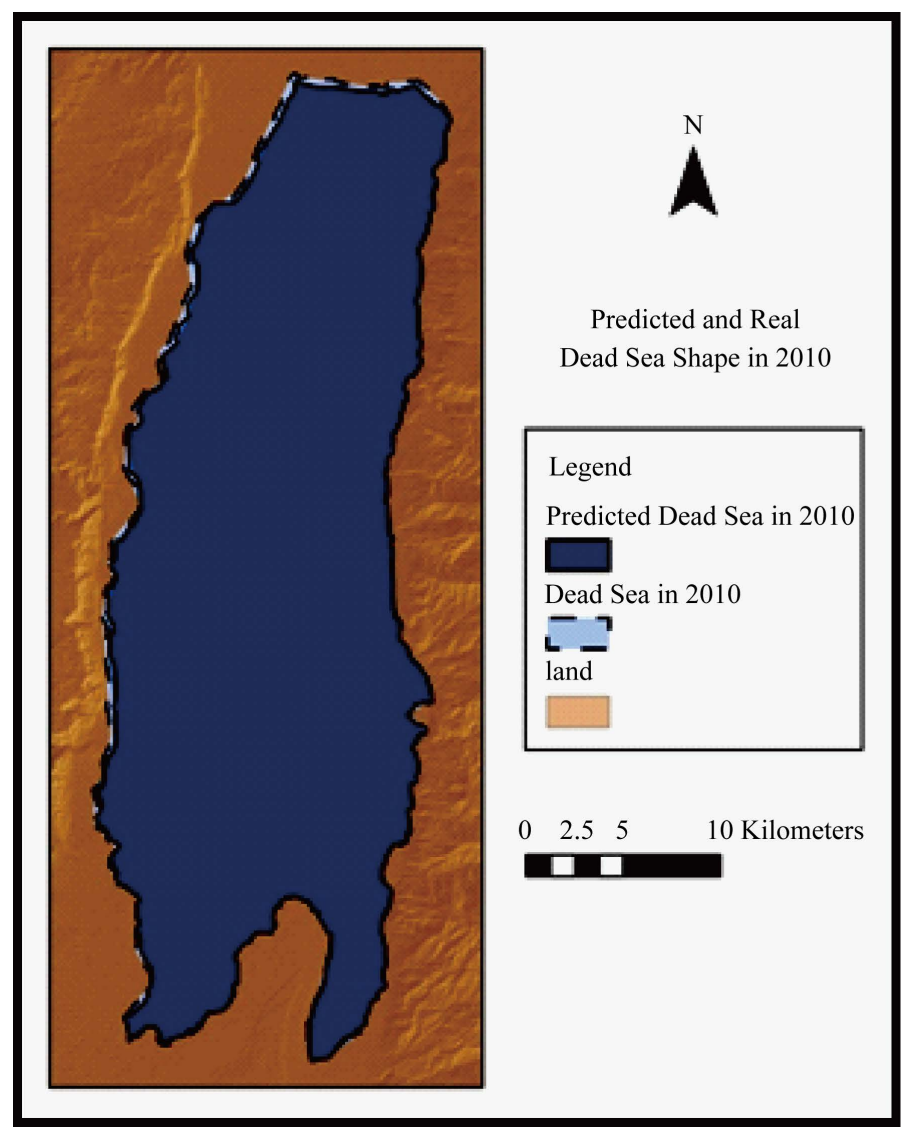

Figure 10. The predicted and real Dead Sea shape in 2010. 
specifications that anticipate your paper as one part of the entire journals, and not as an independent document. Please do not revise any of the current designations.

The percentage between both areas is $2.8 \%$ which so close to quantity disagreement since the difference could be due to some pixels generated in arbitrary locations (not inside the water-body) when using these stochastic algorithms. Strata disagreement $=0$ which is logical because the number of output classes is the same as the number of input classes. The allocation disagreement $=0.0009$ which is so close to zero. Since overall disagreement is 0.0218 , the overall agreement is 0.9782 . The overall agreement consists of agreement due to chance, agreement due to quantity and agreement due to grid cell level location. The agreement due to chance is the agreement that a scientist could achieve with no information of location and no information of quantity. Therefore, it could be a good baseline upon which to compare the actual agreement. The agreement due to chance equals 0.5 . While the agreement due to grid cell level location which is the additional agreement when the comparison map is somewhat accurate in terms of its specification of the grid cell-level location of each category within each stratum. The agreement due to grid cell level location equals 0.4575 . The agreement is due to quantity which is the additional agreement when the comparison map is somewhat accurate in terms of its specification of quantity of each category. The agreement due to quantity equals 0.0207 . There is no additional agreement when the comparison map is somewhat accurate in terms of its specification of quantity of each category within each stratum.

Another factor commonly used in the literatures which measures of agreement between maps called $M(m)$. It describes the agreement between the reference map and the unmodified comparison map. It is the proportion of grid cells classified correctly. It confounds agreement due to quantity and agreement due to location. IDRISI gives $M(m)=0.9782$ which is considered a good matching. Figure 11 describes all these spatial statistics in number format and illustrates these values as a graphical bar shown in the left of the figure.

Based on these results, the suitability maps and model are valid and will be used to predict 2020, 2030 and 2040 maps as shown in Figure 12. The predicted shapes follow the same conditions from 1984 to 2010. The areas of predicted 2020, 2030 and 2040 are 610, 591 and $574 \mathrm{~km}^{2}$ which are considered a logical extension of the trend from 1984 till 2010. The direction of this shrinkage is from the north, northwest and from the south direction of the northern part due to slopes of bathymetry. No shrinkage is considered from the east direction due to the same reason since the bathymetric slope is so sharp.

\section{Conclusion and Recommendations}

Markov-Cellular Automata is used in prediction process. The predicted shapes of 2020, 2030 and 2040 follow

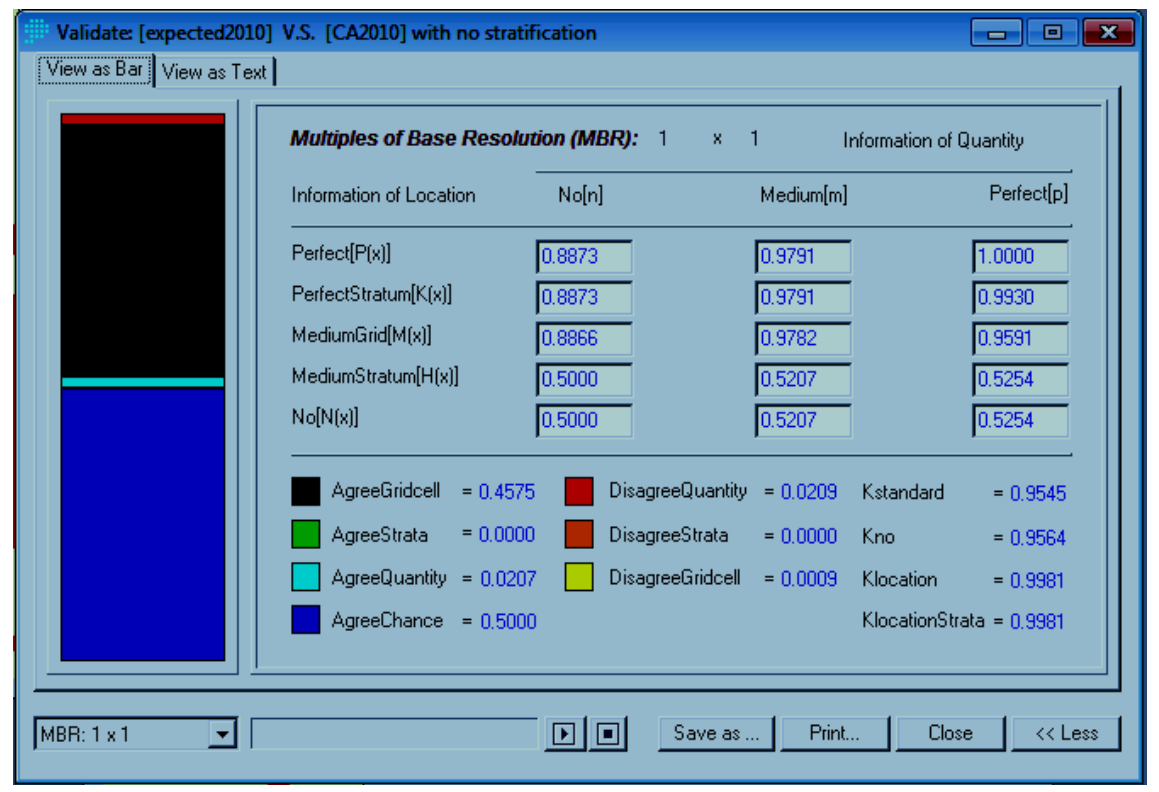

Figure 11. The spatio-statistical output graph generated in validation process. 


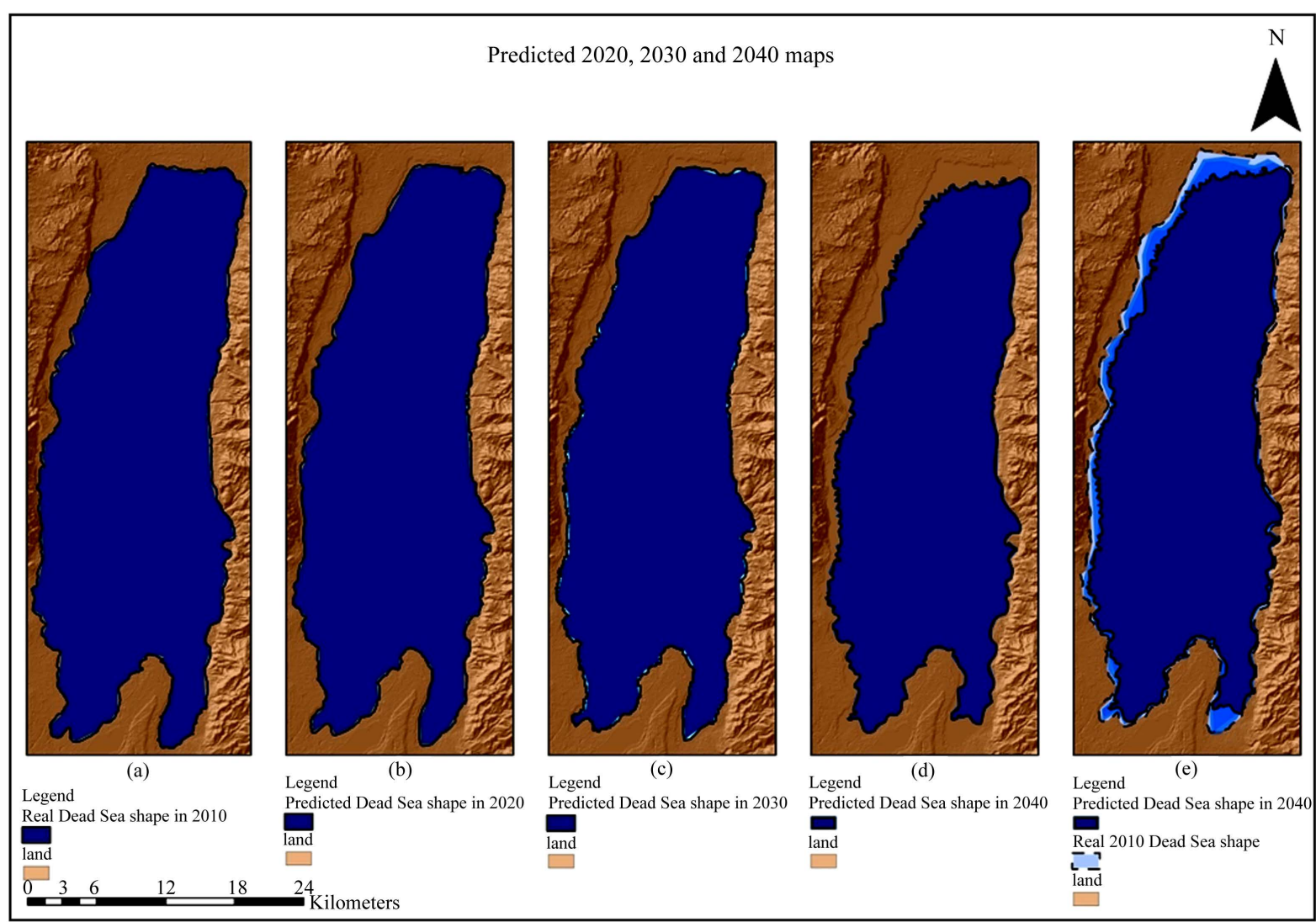

Figure 12. The predicted 2020, 2030 and 2040 maps.

the same conditions from 1984 to 2010. The areas of predicted 2020, 2030 and 2040 are 610,591 and $574 \mathrm{~km}^{2}$ which are considered a logical extension of the trend from 1984 till 2010. So, Markov-Cellular Automata model can be used to predict closed seas as the Dead Sea. It is so recommended to use the result of this study in order to find strategies and solutions to keep the Dead Sea "alive". The result of this spatial simulation model can be used as an environmental alert focusing on the Dead Sea case. It is so recommended to include hydrological parameters in prediction process and to use other surface water models to include Jordan valley in consideration that will give results more reliability.

\section{References}

[1] Eastman, J.R. (2012) IDRISI Selva Manual. IDRISI Tutorial. s.l. Clark University, Worcester. www.clarklabs.org

[2] Tang, J., Wang, L. and Yao, Z. (2007) Spatio-Temporal Urban Landscape Change Analysis Using the Markov Chain Model and a Modified Genetic Algorithm. International Journal of Remote Sensing, 28, 3255-3271. http://dx.doi.org/10.1080/01431160600962749

[3] Briassoulis, H. (2012) Analysis of Land Use Change: Theoretical and Modeling Approaches. Regional Research Institute, Thunder Bay. http://www.rri.wvu.edu/Webbook/Briassoulis/contents.htm

[4] Memarian, H., Balasundram, S.K., Talib, J.B., Sung, C.T.B., Sood, A.M. and Abbaspour, K. (2012) Validation of CAMarkov for Simulation of Land Use and Cover Change in the Langat Basin, Malaysia. Journal of Geographic Information System, 4, 542-554. http://dx.doi.org/10.1080/01431160600962749

[5] Yao, X. (2010) Introduction to Natural Computation: Cellular-Automata. Lecture Notes, University of Birmingham, Birmingham. http://www.cs.bham.ac.uk/internal/courses/intro-nc/current/notes/02-cellular-automata.pdf

[6] Samat, N., Hasni, R., Elhadary, Y. and Eltayeb, A. (2011) Modelling Land Use Changes at the Peri-Urban Areas Using Geographic Information Systems and Cellular Automata Model. Journal of Sustainable Development, 4, $72-84$. http://dx.doi.org/10.1080/01431160600962749

[7] Zhang, Q. (2009) Spatial-Temporal Patterns of Urban Growth in Shanghai, China: Monitoring, Analysis, and Simula- 
tion. Licentiate Thesis, Royal Institute of Technology (KTH), Stockholm.

[8] Wen, W. (2008) Wetland Change Prediction Using Markov Cellular Automata Model in Lore Lindu National Park Central Sulawesi Province, Master Thesis. BOGOR Agricultural University, Bogor.

[9] Cabral, P. and Zamyatin, A. (2006) Three Land Change Models for Urban Dynamics Analysis in Sintra-Cascais Area. 1st EARSeL Workshop of the SIG Urban Remote Sensing, Berlin, 2-3 March 2006, 1-8.

[10] Kushwaha, S.P.S., Nandy, S., Ahmad, M. and Agarwal, R. (2014) Forest Ecosystem Dynamics Assessment and Predictive Modelling in Eastern Himalaya. Elsevier Ecological Indicators Journal, 45, 444-455.

[11] Pontius, R.G. (2000) Quantification Error versus Location Error in Comparison of Catagorical Maps. Photogrammetric Engineering \& Remote Sensing, 66, 1011-1016.

[12] Pontius, R.G. (2002) Statistical Methods to Partition Effects of Quantity and Location during Comparison of Categorical Maps at Multiple Resolutions. Photogrammetric Engineering \& Remote Sensing, 68, 1041-1049.

[13] Pontius, R.G. and Millones, M. (2011) Death to Kappa: Birth of Quantity Disagreement and Allocation Disagreement for Accuracy Assessment. International Journal of Remote Sensing, 32, 4407-4429. http://dx.doi.org/10.1080/01431161.2011.552923

[14] Morin, E. (2009) Flash Flood Prediction in the Dead Sea Region Utilizing Radar Rainfall Data. Journal of Dead-Sea and Arava Research, 1, 14-24.

[15] U.S. Geological Survey (1998) Overview of Middle East Water Resources. Executive Action Team, 41.

[16] El-Hallaq, M.A. and Habboub, M.O. (2014) Using GIS for Time Series Analysis of the Dead Sea from Remotely Sensing Data. Open Journal of Civil Engineering, 4, 386-396. http://dx.doi.org/10.4236/ojce.2014.44033

[17] Green, E.P., Mumby, P.J., Edwards, A.J. and Clark, C.D. (2000) Remote Sensing Handbook for Tropical Coastal Management. UNESCO, Paris. 